\title{
n-DERIVATIONS AND FUNCTIONAL INEQUALITIES WITH APPLICATIONS
}

\author{
Ahmad Alinejad, Hamid Khodaei And Mehdi Rostami
}

Abstract. We prove that every bounded $n$-derivation of a commutative factorizable Banach algebra maps into its radical. Also, the nilpotency of eigenvectors of any bounded $n$-derivation corresponding to its eigenvalues is derived. We introduce the notion of approximate $n$-derivations on a Banach algebra $\mathscr{A}$ and show that the separating space of an approximate $n$-derivation $(n>2)$ is not necessarily an ideal, unless the Banach algebra $\mathscr{A}$ is factorizable. From this and some results on bounded $n$-derivations, we prove that every approximate $n$-derivation of a semisimple factorizable Banach algebra is automatically continuous and every approximate $n$-derivation of a commutative semisimple factorizable Banach algebra is identically zero. Some applications of our results are also provided.

Mathematics subject classification (2010): 47B47, 39B72, 39B82.

Keywords and phrases: $n$th power property, $n$-derivation, Functional inequality, Banach algebra.

\section{REFERENCES}

[1] R. BADora, On approximate derivations, Math. Inequal. Appl., 9, (2006), 167-1731.

[2] R. BADORA, On approximate ring homomorphisms, J. Math. Anal. Appl., 276, (2002), 589-597.

[3] R. BAdora And B. PrZebieracz, On approximate group homomorphisms, J. Math. Anal. Appl., 462, (2018), 505-520.

[4] K. I. Beidar, M. Brešar, M. A. Chebotar and W. S. Martindale 3Rd, On Herstein's Lie map conjectures II, J. Algebra, 238, (2001), 239-264.

[5] D. BRidges And J. Bergen, On the derivation of $x^{n}$ in a ring, Proc. Amer. Math. Soc., 90, (1984), $25-29$.

[6] J. BRZDȨK AND K. Ciepliński, Hyperstability and superstability, Abstr. Appl. Anal., (2013), Article ID 401756.

[7] J. BRZDȨK AND A. FoS̆NER, Remarks on the stability of Lie homomorphisms, J. Math. Anal. Appl., 400, (2013), 585-596.

[8] J. BRZDȨK, D. PopA, I. RAşA And B. Xu, Ulam Stability of Operators, Academic Press, Elsevier, Oxford, 2018.

[9] Q. Chen, X. FAng And C. LI, Jordan $(\alpha, \beta)$-derivations on operator algebras, J. Function Spaces, (2017), Article ID 4757039.

[10] P. J. Cohen, Factorization in group algebras, Duke Math. J., 26, (1959), 199-205.

[11] H. G. DALEs, Banach Algebra and Automatic Continuity, Oxford University Press, Oxford, 2000.

[12] M. Eshaghi Gordji, J. M. Rassias And N. Ghobadipour, Generalized Hyers-Ulam stability of generalized ( $n, k)$-derivations, Abst. Appl. Anal., (2009), Article ID 437931.

[13] A. Fošner AND J. VUKMAn, On some functional equations in rings, Commun. Algebra, 39, (2011), 2647-2658.

[14] R. Gholami, Gh. Askari And M. Eshaghi Gordji, Stability and hyperstability of orthogonally ring $*$-n-derivations and orthogonally ring $*$-n-homomorphisms on $C^{*}$-algebras, J. Linear Topol. Algebra, 7, (2018), 109-119.

[15] H. M. Kim AND I. S. CHANG, Approximate linear derivations and functional inequalities with applications, Appl. Math. Lett., 25, (2012), 830-836. 
[16] H. M. Kim And I. S. Chang, Asymptotic behavior of generalized $*$-derivations on $C^{*}$-algebras with applications, J. Math. Phys., 56, (2015), 041708.

[17] D. C. Kleinecke, On operator commutators, Proc. Amer. Math. Soc., 8, (1957), 535-536.

[18] C. Lanski, Generalized derivations and nth power maps in rings, Commun. Algebra, 35, (2007), 3660-3672.

[19] K. S. LiU, A theorem on derivations on prime rings, J. Aust. Math. Soc., 91, (2011), 219-229.

[20] T. Miura, G. Hirasawa AND S. E. TAKAhasi, A perturbation of ring derivations on Banach algebras, J. Math. Anal. Appl., 319, (2006), 522-530.

[21] C. PARK, Bi-additive s-functional inequalities and quasi-*-multipliers on Banach algebras, Bull. Braz. Math. Soc., 50, (2019), 561-574.

[22] C. PARK, Symmetric biderivations on Banach algebras, Indian J. Pure Appl. Math., 50, (2019), 413426.

[23] C. PARK, Additive $\rho$-functional inequalities and equations, J. Math. Inequal., 9, (2015), 17-26.

[24] C. PARK AND M. TH. RASSIAS, Additive functional equations and partial multipliers in $C^{*}$-algebras, RACSAM, 113, (2019), 2175-2188.

[25] C. PARK AND TH. M. Rassias, Homomorphisms and derivations in proper JCQ* -triples, J. Math. Anal. Appl., 337, (2008), 1404-1414.

[26] J. RoH AND I. S. ChANG, Asymptotic aspect of derivations in Banach algebras, J. Ineq. Appl., (2017), 2017 (1): 36.

[27] M. H. SatTari, On n-derivations, Sahand Commun. Math. Anal., 3, (2016), 107-115.

[28] F. V. SHIROKOV, Proof of a conjecture of Kaplansky, Uspekhi. Mat. Nauk., 11, (1956), 167-168 (in Russian).

[29] A. M. Sinclair, Automatic Continuity of Linear Operators, London Math. Soc., Lecture Notes Series 21, Cambridge University Press, Cambridge, 1976.

[30] I. M. Singer AND J. Wermer, Derivations on commutative normed algebras, Math. Ann., 129, (1955), 260-264.

[31] M. P. Thomas, The image of a derivation is contained in the radical, Ann. Math., 128, (1988), 435-460.

[32] J. Vukman And I. Kosi-Ulbl, A note on derivations in semiprime rings, Int. J. Math. Math. Sci., 20, (2005), 3347-3350.

[33] D. YANG, Jordan *-derivation pairs on standard operator algebra and related results, Colloq. Math., 102, (2005), 137-145. 